\title{
Hipertrigliseridemi ilişkili akut pankreatit hastalarının değerlendirilmesi
}

\author{
Evaluation of hypertriglyceridemia-induced acute pancreatitis
}

\author{
Altay KANDEMIR, Adil COŞKUN \\ Adnan Menderes Üniversitesi Tıp Fakültesi, Gastroenteroloji Bilim Dalı, Aydın
}

\begin{abstract}
Giriş ve Amaç: Hipertrigliseridemi, akut pankreatitin en yaygın üçüncü sebebidir. Bu çalışmanın amacı, hipertrigliseridemi ilişkili akut pankreatit tanısı konulan hastaların karakteristiklerini, tekrar ortaya çıkma sıklığı ve mortalitesini araştırmaktır. Gereç ve Yöntem: Ocak 2010 - Ağustos 2017 tarihleri arasında şiddetli hipertrigliseridemi ilişkili akut pankrea-

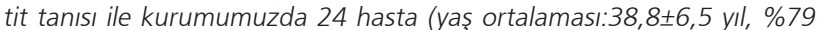
erkek) tedavi edildi. Şiddetli hipertrigliseridemi ilişkili akut pankreatiti değerlendirmek için açlık lipid profili, amilaz, lipaz değerleri ve hasta demografik verileri kaydedildi. Bulgular: Çalışma periyodu sırasında kurumumuza akut pankreatit tanısı ile 615 hasta kabul edildi. Şiddetli hipertrigliseridemi ilişkili akut pankreatiti olan hasta sayısı $24(\% 3,9)$ idi. Tüm hastalarda, medikal tedavi sonrası [standart tedavi ile terapötik plazma aferezi (20 hasta) veya sadece standart tedavi (4 hasta)] trigliserid düzeylerinde anlamlı iyileşme oldu. Bizim hastaların hipertrigliseridemi ile ilişkili olarak bilinen durumlardan, $\% 41,6$ 'sında diyabetes mellitus, \%16,6'sında bozulmuş glukoz toleransı, \%25'inde aşırı alkol alımı, \%8,3'ünde hamilelik vardı. Hastane mortalitesi \%4,1, rekürren pankreatit ise \%29 idi. Sonuç: Rekürren pankreatit oranı yüksek saptandı. Bu, düzensiz fibrat kullanımı, diyet uyumumun zayıf olması, kötü kan şekeri regülasyonu, hamilelik ile ilişkili olabilir. Mortalite oranı \%4,1 idi. Bu kısmen bizim multidisipliner takım çalışması sayesinde, serum trigliserid düzeyinin agresif düzeltilmesinden dolayı olabilir. Şiddetli hipertrigliseridemi ilişkili akut pankreatit hızlıca tedavi edilmelidir. Eğer terapötik plazma afarezine ulaşılabiliyor ise trigilserid düzeyi $<500 \mathrm{mg} /$ dl olana kadar yapılmalıdır.
\end{abstract}

Anahtar kelimeler: Akut pankreatit, hipertrigliseridemi, amilaz

\section{GíRis}

Akut pankreatit (AP) potansiyel olarak hayatı tehdit eden, dünya çapında insidansı artan akut inflamatuvar bir hastalıktır (1). Hipertrigliseridemi (HTG), akut pankreatitin safra taşı ve alkolden sonra en yaygın üçüncü sebebi olup, \%1-4'ünden sorumludur (2). Hiperlipidemik hastaların ise \%12-38'inde AP görülmektedir (3). Trigiliserid (TG) $1000 \mathrm{mg} / \mathrm{dl}$ 'den daha fazla düzeylerde olduğu zaman pankreatit için risk oluşturur ve ciddi komplikasyonlara sebep olabilir (4). Mortalite oranı interstisyel ödematöz pankreatiti olanlarda \%3 iken, pankreatik nekroz gelişen hastalarda \%17'dir $(5,6)$. HTG primer (Fredrickson sınıf-

Iletişim: Altay KANDEMiR

Adnan Menderes Üniversitesi Tıp Fakültesi,
Background and Aims: Hypertriglyceridemia is the third most common cause of acute pancreatitis. This study investigated the characteristics and outcomes (recurrence and mortality) of patients presenting with hypertriglyceridemia-induced acute pancreatitis. Materials and Methods: A total of 24 patients (average age: $38.8 \pm 6.5$ years, $79 \%$ males) treated at our institution for severe hypertriglyceridemia-induced acute pancreatitis between January 2010 and August 2017 were included in this study. Complete fasting lipid profiles, amylase and lipase levels, and patient demographics were recorded for the evaluation of severe hypertriglyceridemia-induced acute pancreatitis. Results: A total of 615 patients were admitted with acute pancreatitis in our institution within the study period. Severe hypertriglyceridemia-induced acute pancreatitis was present in 24 patients (3.9\%). All patients showed significant improvement in their triglyceride levels with medical treatment [therapeutic plasmapheresis with standard treatment (20 patients) or only standard treatment (4 patients)]. Of these patients $41.6 \%$ had type 2 diabetes mellitus, $16.6 \%$ had impaired glucose tolerance, 25\% displayed excessive alcohol use, and $8.3 \%$ were pregnant. All these conditions are known to be associated with hypertriglyceridemia. Hospital mortality was $4.1 \%$, and recurrent pancreatitis was detected in $29 \%$ of the patients. Conclusions: A high rate of recurrent pancreatitis was observed, which may be related to irregular drug use, lack of diet compliance, poor blood glucose regulation, and pregnancy. The low mortality rate of $4.1 \%$ in this cohort may partly be due to aggressive serum triglyceride lowering through a multidisciplinary team. Patients with severe hypertriglyceridemia-induced acute pancreatitis should be treated quickly. If therapeutic plasma exchange is available, triglyceride levels should be lowered to $<500 \mathrm{mg} / \mathrm{dl}$.

Key words: Acute pancreatitis, hypertriglyceridemia, amylase

Gastroenteroloji Bilim Dalı, Aydın

Tel: +90 25644412 56/3159 • E-mail: altaykandemir@yahoo.com lamasına göre tip I, IV ve V ) ya da sekonder meydana gelir. Sekonder HTG, alkol kullanımı, diyabetes mellitus (DM), hamilelik, obezite, hipotiroidizm, nefrotik sendrom ve bazı ilaçlara ( $\beta$ blokörler, oral retinoidler vb.) bağlı meydana gelebilir $(2,7)$.

Hipertrigliseridemi ilişkili akut pankreatitin (HTG-AP) patofizyolojisi tam olarak bilinmemektir. Fazla miktardaki trigliseridlerin pankreatik lipaz ile hidrolizi sonucunda yüksek konsantasyonda serbest yağ asidleri ortaya çıkar. Serbest yağ asidleri toksiktir ve asiner hücreleri ve kapiller endoteli yıkar $(8,9)$. Üstelik artmış şilomikron konsantrasyonu 
damarın vizkositesini arttırır, pankreastaki kan akımının bozulması pankreas içinde iskemi ve asidoza sebep olur (10). Asidozdaki yağ asidleri tripsinojeni aktifleştirir ve akut ödemi ve nekrotizan pankreatiti başlatır $(8,9)$.

AP tanısı için; karın ağrısı, serum amilaz ve lipaz seviyesinin üç katı ve üzeri artışı, spesifik radyolojik bulgulardan oluşan kriterlerin en az iki tanesinin bulunması gerekmektedir (11). Ayrıca artmış TG düzeyi ve HTG medikal hikayesi de HTG'yi etiyolojik faktör olarak düşündürür.

Amacımız, tek merkez, retrospektif bu çalışmada HTGAP'li hastalarımızın demografik verilerini, yapılan tedavinin etkinliğini, hastalığın gidişatını (tekrar akut pankreatit geçirme, ölüm) değerlendirmektir.

\section{GEREÇ ve YÖNTEM}

Ocak 2010 ve Ağustos 2017 tarihleri arasında Adnan Menderes Üniversitesi Tıp Fakültesi Gastroenteroloji kliniğinde, HTG-AP tanısı konulan 24 hasta çalışmaya alındı. Hastaların tüm bilgileri elektronik medikal kayıtlardan retrospektif olarak elde edildi.

HTG-AP tanısı, TG düzeyi 1000 mg/dl üzerinde olması ve akut pankreatit için tanı kriterlerinin (abdominal ağrı, serum lipazın >3 kat üzerinde olması, görüntüleme yöntemlerinde karakteristik bulgular) 3'ünden en az ikisinin bulunması ile konuldu.

Hastaların yaş, cinsiyet, tansiyon, nabız, ateş durumu, alkol ve sigara kullanım öyküsü, DM varlığı, daha önce AP atağı geçirip geçirmediği, daha önce hiperlipidemi tanısı için medikal tedavi alıp almadığı, terapötik plazma afarezi (TPA) yapılıp yapılmadığı, tedavi sonrası kaç yıldır tekrar atak geçirmediği (hastalar tekrar değerlendirilerek) kaydedildi. Ayrıca açlık kan glukozu, kan üre nitrojen (BUN), kreatinin, kalsiyum (Ca), alanin amino transferaz $(A L T)$, gama glutamil transferaz (GGT), laktik dehidrogenaz (LDH), troid stimulan hormon (TSH), amilaz (başvuru anında ve başvurunun 3. günü), lipaz (başvuru anında ve başvurunun 3. günü), TG (başvuru anında ve başvurunun 3. günü), kolesterol (başvuru anında ve başvurunun 3. günü), C-reaktif protein (CRP), sedimentasyon, lökosit, hemoglobin, trombosit değerleri toplandı. Hastaların akut pankreatit durumunu değerlendirmek amaciyla Acute Physiology and Chronic Health Evaluation II (APACHI II skoru), Ranson skoru (kabulde ve 48. saatte) ve abdominal bilgisayarlı tomografide Balthazar klasifikasyonu bakılarak kaydedildi. Tüm sonuçlar yüzde ve meanıstandart deviasyon olarak ifade edildi. İstatistiksel analiz için Ki-kare ve Friedman testleri kullanıldı. Tanımlayıcı istatistikler \% olarak gösterildi ve $p<0.05$ değeri istatistiksel olarak anlamlı kabul edildi.

\section{Terapötik Plazma Aferez Prosedürü}

Tüm TPA prosedürlerinde Haemonetics MCS+ apparat kullanıldı. Periferik venden damar yolu uygun olmadığı durumlarda santral venöz kateter (tek veya çift lümen kateter) kullanıldı. Her TPA prosedürü sırasında bir (nadiren iki defa) plazma volümü değişti ve $30 \mathrm{~g} / \mathrm{l}$ albümin ile beraber bikarbonat bazlı elektrolid solüsyonu ile replasman yapıldı. Plazma afarezinde antikoagülasyon unfraksiyone heparin veya trisodyum sitrat ile yapıldı.

\section{BULGULAR}

AP tanısı konulan 615 hastanın 24'ü $(\% 3,9)$ HTG-AP idi. Bu hastaların 19'u erkek (\%79) ve 5'i kadın (\%21) olmak üzere yaş ortalaması 38,8 $\pm 6,5$ yıl (28-50 yıl) idi. Erkeklerin yaş ortalaması 40,5 $\pm 6,6$ yıl (29-50 yıl), kadınların 33,8 $\pm 5,1$ yıl (28-40 yıl) idi. Bu hastaların 20'sine standart tedaviye ilaveten TPA yapıldı. 4'üne yalnızca standart tedavi verildi. Hastaların 14 tanesi sigara kullanmamış (\%58,3), 4'ü sigarayı bırakmış (\%16,6), 6'sı sigara içiyor (\%25) idi. Hastaların 6'sında (\%25) düzenli alkol alım öyküsü mevcuttu. Tüm hastalarda tiroid fonksiyon testleri normal değerler aralığında idi. Hiçbir hastada sekonder hipotroidizme ilişkin hiperlipidemi saptanmadı. Hastaların hepsinin Ca'u normal değerler aralığında idi. 10 hastada DM, 4 hastada

\section{Tablo 1. Hasta karakteristiği}

\begin{tabular}{|l|c|}
\hline Parametre & Değer \\
\hline N & 24 \\
\hline Erkek & $19(\% 79)$ \\
\hline Kadın & $5(\% 21)$ \\
\hline Yaş & $38,8 \pm 6,5$ \\
\hline Diabetes Mellitus & $10(\% 41,6)$ \\
\hline Bozulmuş glukoz toleransı & $4(\% 16,6)$ \\
\hline Alkol kullanımı & $6(\% 25)$ \\
\hline Hamilelik & $2(\% 8,3)$ \\
\hline Önceden bilinen HTG öyküsü & $10(\% 41,6)$ \\
\hline Sigara Durumu & \\
\hline - Sigara içmemiş & $14(\% 58,3)$ \\
\hline - Sigarayı bırakmış & $4(\% 16,6)$ \\
\hline - Halen sigara içen & $6(\% 25)$ \\
\hline TPA Tedavisi alan & $20(\% 83,3)$ \\
\hline APACHE II skoru & $4,08 \pm 3,87$ \\
\hline Ranson skoru & $2,37 \pm 1,9$ \\
\hline Rekürren HTG-AP & $7(\% 29)$ \\
\hline Pankreatik nekroz komplikasyonu & $2(\% 8.2)$ \\
\hline Hastane mortalitesi & $\% 4,1$ \\
\hline
\end{tabular}

N: Hasta sayıSI, HTG: Hipertrigliseridemi, TPA: Terapötik plazma afarezi, APACHE II (Acute Physiology and Chronic Health Evaluation II), HTG-AP: Hipertrigliseridemi ilişkili akut pankreatit. 


\begin{tabular}{|l|c|c|c|}
\hline $\begin{array}{l}\text { Tablo 2. Başvuruda ve başvurunun 3. günü medikal tedavi sonrası ortalama lipid değerlerinin ve amilaz-lipaz } \\
\text { değerlerinin karşılaştırilması }\end{array}$ & Paşvuru Sonrası 3. Gün Ortalama & $\%$ Düşüş \\
\hline & Başvuruda Ortalama & P & 69 \\
\hline Trigliserid (mg/dl) & $3.564 \pm 1.050$ & $1.103 \pm 219$ & $<0,01$ \\
\hline Total kolesterol (mg/dl) & $(1.382-24.293)$ & $(111-4.241)$ & 44,7 \\
\hline Amilaz (U/L) & $445 \pm 58$ & $246 \pm 28$ & $<0,01$ \\
\hline Lipaz (U/L) & $(173-765)$ & $(134-458)$ & 66,1 \\
\hline
\end{tabular}

Tablo 3. Hastaların Balthazar klasifikasyon bulguları

\begin{tabular}{|l|c|}
\hline Pankreatit Derecesi (Balthazar skoru) & $\mathbf{N}$ \\
\hline Stage-C & $8(\% 33,3)$ \\
\hline Stage-D & $13(\% 54,1)$ \\
\hline Stage-E & $1(\% 4,1)$ \\
\hline Stage -E+ $\leq \% 30$ nekroz & $1(\% 4,1)$ \\
\hline Stage-D+ > $\% 50$ nekroz & $1(\% 4,1)$ \\
\hline
\end{tabular}

ise bozulmuş glukoz toleransı mevcuttu. DM'lu hastaların 4'ünde tanı sırasında diyabetik ketoasidoz görüldü ve bu hastalara HTG-AP tedavisi yanısıra diyabetik ketoasidoz tedavisi de verildi. Hastaların 10 tanesinin (\%41) önceden bilinen hiperlipidemi öyküsü mevcuttu, bu hastaların 4'ü düzensiz fenofibrat, 6'sı gemfibrozil $600 \mathrm{mg}$ kullanıyordu. Hastaların 7'si (\%29) HTG-AP nedeniyle tedavi aldıktan sonra tekrar atak geçirdi, bu hastaların beşinde düzensiz ilaç kullanma veya ilacını bırakma ve diyete uyum sorunu mevcuttu. Tekrar atak geçiren bu hastaların, birinde gebelik, birinde gebelik ve DM, beşinde sadece DM vardı. 17 hastada ise (\%71) tekrar HTG-AP atağı izlenmedi. Bazal hasta demografik verileri, laboratuvar değerleri ve hastalığın gidişatı ile ilgili veriler Tablo 1'de verilmiştir.

Hastaların başvuruda TG düzeyleri ortalaması $3.564 \pm 1.050$ $(1.382-24.293 \mathrm{mg} / \mathrm{dl}) \mathrm{mg} / \mathrm{dl}$, başvurunun 3. günü medikal tedavi sonrası (standart tedavi veya standart tedavi+TPA) TG düzey ortalaması 1.103 219 (111-4.241 mg/dl) $\mathrm{mg} / \mathrm{dl}$ idi. TG düzeylerinde \%69 düşüş saptandı.

Başvuruda total kolesterol düzeyleri ortalaması $445 \pm 58$ (173-765 mg/dl) mg/dl, başvurunun 3. günü medikal tedavi sonrası (standart tedavi veya standart tedavi+TPA) total kolesterol düzey ortalaması 246 $\pm 28(134-458 \mathrm{mg} /$ dl) $\mathrm{mg} / \mathrm{dl}$ idi. Total kolesterol düzeylerinde $\% 44$ düşüş saptandı.

Amilaz değerleri ortalaması başvuruda 464 100 (47$1.675 \mathrm{U} / \mathrm{L}) \mathrm{U} / \mathrm{L}$ iken, başvurunun 3. günü medikal te- davi sonrası (standart tedavi veya standart tedavi+TPA) 157 \pm 563 (13-1120 U/L ) U/L olarak bulundu. Amilaz değerlerindeki düşüş \%44,7 idi.

Lipaz değerleri ortalaması başvuruda 1951 2201 (2243770 U/L) U/L, başvurunun 3. günü medikal tedavi sonrası (standart tedavi veya standart tedavi+TPA) $426 \pm 72$ (41-1614 U/L ) U/L idi ve lipaz değerindeki düşüş \%78.1 olarak saptandı. Başvuruda ve başvurunun 3. günü medikal tedavi sonrası ortalama trigliserid ve total kolesterol değerlerinin ve amilaz-lipaz değerlerinin karşılaştıııması ile ilgili veriler Tablo 2'de verilmiştir.

Hastaların APACHE || skorları ortalaması 4,08 $\pm 3,87$ (116), Ranson skorları ortalaması 2,37 $\pm 1,9$ (0-8) idi. llımlı pankreatite (APACHE II skoru $<8$ ve Ranson skoru $<4$ ) sahip hasta sayısı $20(\% 83,3)$, şiddetli pankreatite (APACHE II skoru $\geq 8$ ve Ranson skoru $\geq 4$ ) sahip hasta sayısı 4 $(\% 16,7)$ idi. Şiddetli pankreatite sahip hastaların ikisinde pankreatik nekroz gelişti. Bu hastaların birine başvurunun 8. haftasında endoskopik nekrozektomi uygulandı diğer hasta ise solunum yetmezliği ve sepsisden öldü.

Hastaların abdominal bilgisayarlı tomografi (BT) ile Balt-

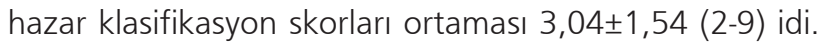
Çoğu hasta (\%54,1, n:13) Balthazar klasifikasyonuna göre grade D pankreatite sahipti. Hastaların Balthazar klasifikasyon bulguları Tablo 3'te verilmiştir.

Hastaların 20'sine TPA uygulandı, 16'sında (\%80) tek seansda, 4'ünde (\%20) 2 seansda TG düzeyi $<1000$ mg/ dl'nin altına indirildi.

Standart tedavi+TPA alanlar ile sadece standart tedavi alan hastalar TG, kolesterol, amilaz ve lipaz düşüşü açlsından karşılaştııılığında aralarında anlamlı fark saptanmadı (Tablo 4 ).

\section{TARTIŞMA}

Ciddi HTG, AP'lerin \%1-4'ünden sorumludur (2). Bizim 


\begin{tabular}{|l|c|c|c|}
\hline \multicolumn{2}{|c|}{ Tablo 4. Standart tedavi ile standart tedavi + TPA'nın etkinliğininin karşılaştırılması } & P \\
\hline & Standart Tedavi+TPA & Standart Tedavi & \\
\hline N & 20 & 4 & $>0,05$ \\
\hline Trigliserid düşüşü (\%) & 69,2 & 66,1 & $>0,05$ \\
\hline Total kolesterol düşüşü (\%) & 46,9 & 29 & $>0,05$ \\
\hline Amilaz düşüşü (\%) & 63,8 & 66,5 & $>0,05$ \\
\hline Lipaz düşüşü (\%) & 78,1 & 81,8 & \\
\hline
\end{tabular}

TPA: Terapötik plazma afarezi

çalışmamızda ciddi hiperlipidemi \%3,9 vakadan sorumlu idi. Mortalite oranı intertisyel ödematöz pankreatiti olanlarda \%3 iken, pankreatik nekroz gelişen hastalarda \%17'dir $(5,6)$. HTG-AP'in ilk başvuru yakınmaları diğer nedenlerle oluşan AP'e benzer şekilde; karın ağrısı, mide bulantısı ve kusmadır. Kötü kontrol altındaki DM, alkolizm, obezite, gebelik, önceden pankreatit öyküsü ve kişisel veya ailede hiperlipidemi öyküsü HTG-AP tanısını düşündürmelidir (2).

Bazı çalışmalar, HTG-AP'li hastaların genel olarak diğer nedenlerle oluşan AP'li hastalara göre daha genç yaşta olduğunu göstermiştir (12). Bizim çalışmamızda da yaş ortalaması 38,8 $\pm 6,5$ yll (28-50 yıl) bulundu. HTG-AP'in seyri ile ilgili veriler çelişkilidir. Bazı çalışmalarda HTG$A P^{\prime}$ de hastalığın klinik gidişatının diğer etiyolojilerle olan AP'lerden farklı olmadığı (2) söylenmesine rağmen başka çalışmalar daha şiddetli hastalık (13-14) ve daha yüksek mortalite (15) ile ilişkili raporlar yayınlamışlardır.

Alkol HTG-AP'i tetikleyebilir. HTG-AP'in doğrudan sebebi olarak mı, yoksa altta yatan genetik hiperlipidemiyi alevlendirerek mi sebep olduğu açık değildir (16). Alkol TG düzeylerini doz bağımlı olarak arttırır. Bizim hastalarımızın 6 'sında (\%25) düzenli alkol alım öyküsü mevcuttu. Hipotroidi HTG-AP'in sekonder sebebidir (17). Bizim vakalarımızın hiçbirinde sekonder hipotroidi bulgusuna rastlanmadı. Gebelikte akut pankreatit nadir görülür. Chang ve ark. nın yaptığı çalışmada gebelik sırasında meydana gelen AP vakalarının \%56'sından HTG sorumlu bulunmuştur (18). Bizim çalışmamızda 2 hasta gebelik sırasında HTG-AP atağı geçirdi. DM tip 1 ve 2 ile diyabetik ketoasidoz HTGAP'yi tetikleyebilir (19-20). Retrospektif bir çalışmada, 12 yaş üstü 70 HTG-AP olgusunun altta yatan en sık nedeni, kötü kontrollü DM ile ilişkili HTG idi (2). Çalışmamızda 10 hastada $(\% 41,6)$ DM, 4 hastada $(\% 16,6)$ bozulmuş glukoz toleransı saptandı. DM olan hastaların 4'ünde HTGAP atağı sırasında diyabetik ketoasidoz mevcuttu.

HTG-AP'de tedavi diğer sebeplerle oluşmuş akut pankreatit ile aynıdır. Standart AP tedavisinin yanında ilk amaç TG düzeyini $<500$ mg/dl altına indirmek olmalıdır. Stan- dart tedavi, oral alımın kesilmesi, intravenöz sıvı desteği, analjezik ile ağrı kontrolüdür. Spesifik tedaviler ise TG düzeylerini düşürmek için TPA $(21,22)$ yanı sıra insülin ve heparindir $(23,24)$. Aynı zamanda renal fonksiyonlar moniterize edilir ve septik şok açısından yakın takip edilir. İnsülin lipoprotein lipazı aktive ederken, heparin sirkülasyona giren endotelial lipoprotein lipazın salınımını stimüle eder. Böylece plazmadan şilomikronların klirensi artar. Öte yandan TPA, plazmadan TG'leri hızı bir şekilde uzaklaştırır, bu yüzden en etkili ve mantıklı tedavi yöntemi olarak görülmektedir. En son kılavuzlarında (25) American Society for Apheresis, akut hipertrigliseridemik pankreatiti kategori III endikasyon olarak görmektedir. Eğer ulaşılabiliyor ve hasta tolere ediyor ise TPA düşünülmelidir (21).

TPA kullanan merkezler için tedavinin erken başlatılmasının önemli olabileceği önerilmiştir (26).Tek plazma değişimi serum TG düzeyini \%49-80 arasında azaltabilir fakat bazı hastalarda TG düzeyini 1.000 mg/dl altına indirmek için iki veya daha fazla seansa ihtiyaç olmaktadır. Yeh ve ark (27) ile Lennertz ve ark. (28) tek seansda TG düzeylerini \%70'e kadar düşürerek açık bir şekilde hem klinik hem de laboratuvarda iyileşme sağlamışlardır. Kadıköylü ve ark.nın yaptıkları çalışmada TPA sonrası TG düzeyinde $\% 46,1$ ve total kolesterol düzeylerinde $\% 50,8$ azalma sağlamışlardır (29). Bizim çalışmamızda 20 hastaya TPA yapıldı, tek seans TPA sonrası TG düzeyinde $\% 69,2$, total kolesterol düzeyinde ise \%46,9 düşüş sağlandı. İkinci seans TPA sonrası TG düşüşü ise $\% 87,8$ saptandı. 16 hastanın (\%80) TG düzeyi tek seansda $<1.000$ mg altına inerken, 4 hastada (\%20) 2 seans sonrası TG düzeyi $<1.000$ mg altına indi. Chen ve ark.nın yaptıkları daha geniş bir retrospektif çalışmada ise HTG-AP'li hastalar, plazma değişimi yapılan ve yapılmayan olarak iki gruba ayrılmış, mortalite ve morbideteleri karşılaştırılmış, iki grup arasında anlamlı bir fark saptanmamıştır (26). Bizim çalışmamızda 20 hastada TPA+ standart tedavi verildi, 4 hastada ise sadece standart tedavi verildi. Bu iki grup karşılaştırıldığında; TG, total kolesterol, amilaz ve lipaz değerlerinin düşüşünde anlamlı farklılık bulunmadı. Standart tedavi alan hasta sayımızın 4 olması nedeniyle, daha geniş hasta 
sayısı ile yapılan randomize klinik çalışmalara intiyaç olduğu kanaatindeyiz. TPA+Standart tedavi verilen grupta ılımlı pankreatitli hastalarda komplikasyon izlenmez iken şiddetli pankreatite (APACHI II skoru $\geq 8$, Ranson skoru $\geq 4$ ) sahip hastaların ikisinde pankreatik nekroz izlendi, bu hastaların birisine 8 . haftada endoskopik nekrozektomi tedavisi uygulanırken, diğeri solunum yetmezliği ve septisemiden ex oldu. Yalnızca standart tedavi alan 4 hastada komplikasyon izlenmedi. Tedavi sonrası tüm hastalar endokrinoloji kliniğine konsülte edilerek fibrat ve diyet tedavisine başlandı. Bu hastaların 16'sına gemfibrozil $600 \mathrm{mg}$ tb başlanırken, 8'ine fenofibrat $267 \mathrm{mg}$ tb başlandı. Tekrar ciddi HTG-AP atağından kaçınmak için endokrinoloji

\section{KAYNAKLAR}

1. Singla A, Csikesz NG, Simons JP, et al. National hospital volume in acute pancreatitis: analysis of the Nationwide In patient Sample 1998-2006. HPB (Oxford) 2009;11:391-7.

2. Fortson MR, Freedman SN, Webster PD 3rd. Clinical assessment of hyperlipidemic pankreatitis. Am J Gastroenterol 1995; 90:2134-9.

3. Searles GE, Ooi TC. Under recognition of chylomicronemia as a cause of acute pancreatitis. CMAJ 1992;147:1806-8.

4. Berglund L, Brunzell JD, Goldberg AC, et al; Endocrine society. Evaluation and treatment of hypertrglyceridemia: an Endocrine Society clinical practice guidline. J Clin Endocrinal Metab 2012;97:2969-89.

5. Sing VK, Bollen TL, Wu BU, et al. An assesment of the severity of intestitial pancreatitis. Clin Gastroenterol Hepatol 2011; 9:1098-103.

6. Van Santvoort HC, Bakker OJ, Bollen TL, et al; Dutch Pancreatitis Study Group. A conservative and minimally invasive approach to necrotizing pancreatitis improves outcome. Gastroenterology 2011;141:1254-63.

7. Brunzell JD, Schrott HG. The interaction of familial and secondary causes of hypertriglyceridemia: role in pancreatitis. J Clin Lipidol 2012;6:409-12.

8. Yadav D, Pitchumoni CS. Issues in hyperlipidemic pancreatitis. J Clin Gastroenterol 2003;36:54-62.

9. Halangk W, Lerch MM, Brandt-Nedelev B, et al. Role of cathepsin $B$ in intracellular trypsinogen activation and the on set of acute pancreatitis. J Clin Invest. 2000;106:773-81.

10. Zeng $Y$, Wang $X$, Zhang $W$, et al. Hypertriglyceridemia aggravates ER stress and pathogenesis of acute pancreatitis. Hepatogastroenterology 2012;59:2318-26.

11. Banks PA, Bollen TL, Dervenis C, et al; Acute Pancreatitis Classification Working Group. Classification of acute pancreatitis. 2012: revision of the Atlanta classification and definitions by international consensus. Gut 2013;62:102-11.

12. Sekimoto M, Takada T, Kawarada Y, et al. JPN Guidelines for the management of acute pancreatitis: epidemiology, etiology, natural history, and outcome predictors in acute pancreatitis. J Hepatobiliary Pancreat Surg 2006;13:10-24.

13. Baranyai $T$, Terzin V, Vajda A, et al. Acute pancreatitis caused by hypertriglyceridemia. Orv Hetil 2010;151:1869-74.

14. Lloret Linares $C$, Pelletier AL, Czernichow S, et al. Acute pancreatitis in a cohort of 129 patients referred for severe hypertriglyceridemia. Pancreas 2008;37:13-2. kliniğinin takibine girmesi sağlanarak izleme alındı. Fakat hastalarımızın 7'sinde (\%29) takipte tekrar HTG-AP atağı izlendi, bunlar değerlendirildiğinde 5'inde diyet ve fibrat kullanımı düzenli değildi. 5'inde sadece DM, 1'inde gebelik, 1'inde gebelik ve DM mevcuttu. 17 hastada (\%71) tekrar HTG-AP atağı izlenmedi.

Sonuç olarak HTG, AP'li tüm hastalarda düşünülmeli ve DM, alkolizm, obezite, gebelik, önceden pankreatit öyküsü ve kişisel veya ailede hiperlipidemi öyküsü sorgulanmalıdır. Şiddetli HTG-AP'li hastalarda, TPA'in erken uygulanması için kesin kanıt olmamasına rağmen, eğer TPA'ne ulaşılabiliyor ise standart tedavi ile birlikte TPA'nın klinik gidişatı iyileştirmede yararı olduğu açıktır.

15. Deng LH, Xue P, Xia Q, et al. Effect of admission hypertriglyceridemia on the episodes of severe acute pancreatitis. World J Gastroenterol 2008;14:4558-61.

16. Toskes PP. Hyperlipidemic pancreatitis. Gastroenterol Clin North Am 1990;19:783-91.

17. O'Brien T, Dinneen SF, O'Brien PC, et al. Hyperlipidemia in patients with primary and secondary hypothyroidism. Mayo Clin Proc 1993;68:860-6.

18. Chang CC, Hsieh YY, Tsai HD, et al. Acute pancreatitis in pregnancy. Zhonghua Yi Xue Za Zhi (Taipei) 1998;61:85-92.

19. Havel RJ. Familial dysbetalipoproteinemia. New aspects of pathogenesis and diagnosis. Med Clin North Am 1982;66:441-54.

20. Nair S, Yadav D, Pitchumoni CS. Association of diabetic ketoacidosis and acute pancreatitis: observations in 100 consecutive episodes of DKA. Am J Gastroenterol 2000; 95:2795-800.

21. Tsuang W, Navaneethan $U$, Ruiz L, et al. Hypertriglyceridemic pancreatitis: presentation and management. Am J Gastroenterol 2009;104:984-91.

22. Henzen C, Röck M, Schnieper C, Heer K.Heparin and insulin in the treatment of acute hypertriglyceridemia-induced pancreatitis. Schweiz Med Wochenschr 1999;129:1242-8.

23. Betteridge DJ, Bakowski M, Taylor KG, et al. Treatment of severe diabetic hypertriglyceridaemia by plasma exchange. Lancet 1978;311:1368.

24. Gubensek J, Buturovic-Ponikvar J, Marn-Pernat A, et al. Treatment of hyperlipidemic acute pancreatitis with plasma exchange: a single-center experience. Ther Apher Dial 2009;13:314-7.

25. Schwartz J, Winters JL, Padmanabhan A, et al. Guidelines on the use of therapeutic apheresis in clinical practice-evidence-based approach from the writing committee of the American Society for Apheresis: the sixth special issue. J Clin Apher 2013;28:145-284.

26. Chen JH, Yeh JH, Lai HW, Liao CS. Therapeutic plasma exchange in patients with hyperlipidemic pancreatitis. World J Gastroenterol 2004; 10:2272-4.

27. Yeh JH, Chen JH, Chiu HC. Plasmapheresis for hyperlipidemic pancreatitis. J Clin Apher 2003;18:181-5.

28. Lennertz A, Parhofer KG, Samtleben W, Bosch T. Therapeutic plasma exchange in patients with chylomicronemia syndrome complicated by acute pancreatitis. Ther Apher 1999;3:227-33.

29. Kadikoylu G, Yavasoglu I, Bolaman Z. Plasma exchange in severe hypertriglyceridemia a clinical study. Transfus Apher Sci 2006;34:253-7. 